\title{
PARENTAL PERCEPTION OF THE IMPORTANCE OF THE PRIMARY DENTITION AND CHILDREN'S CARIES EXPERIENCE
}

C.H. Law, I.A. Razak, R. Saub. Parental perception of the importance of the primary dentition and children's caries experience. Annal Dent Univ Malaya 2000; 7: $11-15$.

\section{ABSTRACT}

A cross-sectional study was conducted to ascertain the relationship between parental oral health perception on the importance of the deciduous dentition and the dental caries status of their preschool children. Clinical oral examination of the preschool children was performed and self-administered questionnaires were given to the parents to be completed. Four hundred and eight preschool children were examined and 390 of their parents responded to the self-administered questionnaire. Those parents who brought their children for regular dental check-up at least once a year; favoured restorative treatment and practised tooth brushing habit before bedtime were more likely to have children with significantly lower mean ' $\mathrm{dft}$ ' as well as higher proportions of caries free mouth $(>50 \%)$. Those children who started early in practising tooth brushing also had better dental caries status but the differences were not significant. However, there were no significant and appreciable differences in their mean 'dft' with respect to the frequencies of tooth brushing per day. It was concluded that parents with better oral health perception as reflected by those parents who (a) practiced regular dental check-up for their children; (b) favoured restorative treatment for their children's decayed deciduous teeth; (c) ensured their children brushed their teeth before bedtime are associated with better dental caries status of their preschool children.

Key words: Dental caries status, Preschool children, Parental perception.

\section{INTRODUCTION}

It is generally observed that the dental caries experience in children in Malaysia has declined (1). However this phenomena is not consistent among children in all age groups. Results from the most recent National Epidemiological survey of 5 year-old preschool children have indicated that the caries experience is still considerably high (2). The mean teeth affected with caries was about 6 teeth per person $(\mathrm{dft}=5.8)$. This situation had remained unchanged from the 1988 Epidemiological survey of 6 year-olds (3).

Several studies have shown that parental factors are associated with dental caries of their preschool children $(4,5,6,7,8)$. Parental perception of the importance of decidous dentition, which is reflected through the
Original Article

\author{
C.H. Law ${ }^{1}$, I.A. Razak ${ }^{2}$ and R. Saub 2 \\ ${ }^{\prime}$ Ministry of Health, Malaysia
}

${ }^{2}$ Department of Community Dentistry

Faculty of Dentistry

University of Malaya,

50603 Kuala Lumpur.

Corresponding author-I.A. Razak

preventive behaviour, was found to be one of the predisposing factors to dental health of the preschool children.

Verrips et al (1992) identified that the age of the child at which the parents had started to brush their child's teeth, the use of fluoride tablets and the regularity of the brushing behaviour in the past were found to be a potential risk factors in developing dental caries (9).

Parents who are concerned about their own oral health will more likely to be also concerned about their child oral health. For example the study conducted by Moynihan and Holt (1996) discovered that significantly less caries were observed in children whose mothers were regular attenders themselves (10). A study by Thomas and Startup (1991) revealed that those mothers who had manifestly delayed their children's first contact with the dental services were much more likely to favour extraction than to save the tooth (11).

Since the prevalence of dental caries among the preschool children in Malaysia is still considerably high, it is important to identify factors that may contribute to the occurrence of the disease. Several studies elsewhere have found that the parental perception of the deciduous dentition was associated with the dental caries incidence among the preschool children Hence this study was undertaken to ascertain this relationship in the local scenario.

\section{METHODS}

Sample:

A convenient sample of 408 six-year-old preschool children and their parents were selected to participate in this study. To obtain the variability of the dental caries status, the sample was selected from two Government $(\mathrm{n}=214)$ and six Private Kindergartens $(\mathrm{n}=194)$ which were located in a fluoridated area. This was done because children in government kindergarten 
were usually from low socioeconomic background where they were more likely to have high dental caries experience and vice versa for children from the private kindergarten. As only 390 parents responded to the questionnaire, the analysis of data was confined to these parents and their children.

\section{Clinical Oral Examination:}

The examination criteria for dental caries were that proposed by the World Health Organisation (12). Dental caries status (dft) and caries free mouth were assessed. Missing teeth for deciduous dentition were not charted to avoid confusion of missing teeth due to caries, trauma or exfoliation of primary teeth. Caries free mouth $(C F M)$ is indicated when ' $\mathrm{dft}^{\prime}=0$. The children were examined using plane mouth mirrors and pencil torchlight in sitting position on the school chairs.

Since only one researcher (C.H.Law) was involved in the oral examination, only intra-examiner calibration of $\mathrm{dft}$ was done to ensure reliability of the oral examination.

Calibration was conducted on 30 six-year-old preschool children from a school that was not part of the final sample. It was carried out twice on 2 different days ( 5 days apart) and the percentage agreement was found to be $97.7 \%$.

\section{Self-Administered questionnaires:}

The questionnaire was formulated based on the literature review and the objective of the study. Pretesting of the questionnaire was carried out on the parents of those 30 subjects who were involved in the calibration exercise to check for ease of understanding, clarity and their sequential flow. Any ambiguity and inadequacies detected were rectified to ensure the reliability of the questionnaire.

The questions were designed to collect information on the reported dental attendance pattern of the children; parental choice of dental treatment for their children's decayed deciduous teeth; their children's age of onset in tooth brushing habit; the frequency of their tooth brushing as well as their tooth brushing habit before bedtime. These constitute a proxy measure of the parental perception on the importance of the deciduous dentition.

\section{Data Management And Analysis:}

Data collected were checked for completeness. The findings obtained were coded and entered into microcomputer. Analysis was done using Statistical Package for Social Sciences (SPSS). Kruskall-wallis tests were used for examining between group differences in means for dft. Chi-squared tests were used for examining between group differences in proportion for caries free mouth (CFM). The significance level was set at $p<$ 0.05 . As the questionnaire has not been fully completed by parents in all instances, the analysis was carried out only in respect of those who responded to that particular question.

\section{RESULTS}

Reported Practice of Dental Visit And Dental Caries Status of The Children (Table I)

Children who practised regular dental check-up at least once a year had significantly better dental caries status and higher proportions of 'caries free mouth' than children who never visited dentists and children who only visited the dentists whenever they had dental problem.

Children whose dental attendance pattern was categorized as "others", had the lowest mean 'dft' and the highest proportion of 'caries free mouth'. Further analysis of this category indicated that some parents claimed to have just started dental check-up recently; some parents personally undertook examination of their children's teeth weekly (home-checking); some stated their children had no dental problem and others said they pulled out their children's milk teeth on their own at home.

\section{Parental Choice Of Dental Treatment For Their Children's Decayed Deciduous Teeth (Table II)}

Parents who preferred dental restoration for their children's decayed deciduous teeth had children with significantly lower mean 'dft' and higher proportions of 'caries free mouth'. Those parents who ignored their children decayed deciduous teeth, had children with the worst dental caries status.

The majority of those who answered as 'others' stated that they had no specific choice of treatment but would follow the dentist's advice on the appropriate dental treatment for their children's decayed milk teeth.

\section{Initiation of Tooth Brushing Habit And Dental Caries Status (Table III). \\ Children whose parents initiated tooth brushing at one year old and younger had comparatively better dental caries status than those parents who started late ( 2 years and above). It was also observed that parents who started to brush their children's teeth at very late age ( 4 years and above) had children with poorest dental caries status. However the difference was not significant.}

\section{Frequency Of Tooth Brushing And Dental Caries Status (Table IV)}

Almost $70 \%$ of the parents claimed that they asked their children to brush twice daily and a very small proportion reported that they did not tell their children to brush daily. There were no significant differences in the mean 'dft' for the different frequencies of daily tooth brushing habit. The finding revealed that there was a reverse association between the frequency of tooth brushing and proportion of 'caries free mouth' and it was statistically significant.

\section{Tooth Brushing Habit Before Bedtime And Dental Caries Status (Table V)}

Those parents who made sure their children brushed their teeth before going to bed had children with lower 
mean 'dft' $(1.82 \pm 2.73)$. However, there was no significant differences in the proportions of'caries free mouth'.

\section{DISCUSSION}

The present study comprised of 408 preschool children from two government and six private kindergartens. The choice of these two categories of kindergartens was made to reflect the generally low and high socioeconomic status of their parents respectively. As the subjects are derived from a convenient sample, the results cannot be generalised to the six-year old Malaysian population. Nevertheless it fills the gap of knowledge on parental perception of the importance of the primary dentition and its relationship to their children's caries experience. Such information is currently lacking in Malaysia.

For the purpose of this study, the "dft" has been taken to reflect the caries status of the children in order to exclude teeth that have been exfoliated. However, this may result in an underestimation of caries status.

In this study, the dental attendance pattern of the children; choice of dental treatment preferred for the children's decayed milk teeth as well as parental supervision of tooth brushing behaviours adopted by their children have been used as a proxy measure for parental perception on the importance of deciduous dentition

Regular dental attendance can be regarded as an expression of a positive dental health attitude and good parental perception on the importance of their children's deciduous dentition. Low dental awareness is usually associated with irregular dental visits (13). The findings of this study revealed that children who had regular dental check-up at least once a year had significantly better dental caries status than those who were symptomatic attenders or who have never visited the dentists (Table I).

Children who practised symptomatic dental visits had significantly higher mean 'dft' than those who never

Table I. Dental attendance pattern and dental caries status

\begin{tabular}{llc}
\hline \begin{tabular}{l} 
Dental Attendance Pattern \\
\multicolumn{1}{c}{$(\mathrm{N}=384)$}
\end{tabular} & \multicolumn{2}{c}{ Dental Caries Status } \\
\cline { 2 - 3 } & $\begin{array}{c}\text { Mean } \\
\mathrm{dft}(\mathrm{s} . \mathrm{d} .)\end{array}$ & $\begin{array}{c}\text { CFM } \\
(\%)\end{array}$ \\
\hline $\begin{array}{l}\text { Regular dental check-up at } \\
\text { least once a year ( } \mathrm{n}=39)\end{array}$ & $1.21(1.79)$ & 53.8 \\
$\begin{array}{l}\text { Whenever my child has } \\
\text { dental problem ( } \mathrm{n}=142)\end{array}$ & $2.67(3.82)$ & 47.2 \\
$\begin{array}{l}\text { Never (n=192) } \\
\text { Others (n=II) }\end{array}$ & $2.18(2.86)$ & 44.8 \\
\hline P-value (*significant) & $0.09(0.30)$ & 90.9 \\
\hline
\end{tabular}

Table II. Choice of dental treatment and dental caries status

\begin{tabular}{|c|c|c|}
\hline \multirow{2}{*}{$\begin{array}{l}\text { Dental Attendance Pattern } \\
\qquad(\mathrm{N}=381)\end{array}$} & \multicolumn{2}{|c|}{ Dental Caries Status } \\
\hline & $\begin{array}{c}\text { Mean } \\
\text { dft (s.d.) }\end{array}$ & $\begin{array}{c}\text { CFM } \\
(\%)\end{array}$ \\
\hline Get it filled $(n=58)$ & $1.33(2.34)$ & 63.8 \\
\hline Get it pulled out $(n=219)$ & $2.15(3.06)$ & 47.9 \\
\hline Ignore the tooth $(n=41)$ & $4.29(4.10)$ & 26.8 \\
\hline Others $(n=63)$ & $1.85(3.12)$ & 49.2 \\
\hline P-value ("significant) & ${ }^{*} 0.000$ & ${ }^{*} 0.004$ \\
\hline
\end{tabular}

visited any dentists. This higher value of mean ' $\mathrm{dft}$ ' could be attributed to higher mean ' $\mathrm{f}$ ' components. However, their overall proportions of "caries free mouth' were significantly higher than those who had never visited the dentists. This may reflect on the poorer parental perception of the latter who never practised any preventive dental health visits or bother to seek any dental treatment to maintain the oral health status of their children.

Parents who claimed that they checked their children's teeth weekly at home and those parents who made an effort to extract their children's own milk teeth had children with significantly better dental caries status. This indicates that they were more likely to be dentally health conscious and practised 'self care' at home.

Children of parents who favoured dental restoration of their children's decayed milk teeth had the best dental caries status (Table II) followed by those who claimed that they would follow the dentist's advice on the appropriate dental treatment for their children's decayed teeth. It seemed that the parental compliance with the dentists' advice had improved or maintained the oral health status of their children.

Parents who favoured extraction or ignored their children's decayed milk teeth had children with higher mean 'dft' (Table II) with lower proportions of 'caries free mouth'. This was a reflection of the poorer parental perception on the importance of their children's deciduous dentition.

Tooth brushing behaviour is so widespread and well accepted that it is regarded as a norm for this country. Tooth brushing behaviour of more than once per day has become the norm for the Malaysian population (14). Children acquired this behaviour through the process of primary socialization (15). In this study (Table III), those parents who started to brush their children's teeth at around one year old had children with comparatively better dental health status than those who started later (especially after 4 years old) but the differences were not significant. Moynihan and Holt (10) reported that dental caries was less likely to occur in children in whom tooth brushing habit commenced before one year old. However, a local study by Dasrilsyah (16) revealed that $51.6 \%$ of parents said that they only started 
Table III. Initiation of tooth brushing habit and dental caries status

\begin{tabular}{lcc}
\hline $\begin{array}{l}\text { Age of onset in practising } \\
\text { tooth brushing habit } \\
(\mathrm{N}=383)\end{array}$ & \multicolumn{2}{c}{ Dental Caries Status } \\
\cline { 2 - 3 } & $\begin{array}{c}\text { Mean } \\
\text { dft (s.d.) }\end{array}$ & $\begin{array}{c}\text { CFM } \\
(\%)\end{array}$ \\
\hline 1 year old or less $(n=93)$ & $1.74(2.79)$ & 55.9 \\
2 years old ( $n=142)$ & $2.39(3.30)$ & 45.1 \\
3 years old ( $n=97)$ & $2.04(2.98)$ & 47.4 \\
4 years old and above ( $n=51)$ & $2.84(3.76)$ & 43.1 \\
\hline P-value ("significant) & ${ }^{*} 0.000$ & $* 0.004$ \\
\hline
\end{tabular}

Table IV. Frequency of tooth brushing and dental caries status

\begin{tabular}{lcc}
\hline $\begin{array}{l}\text { Frequency of tooth brushing } \\
(\mathrm{N}=383)\end{array}$ & \multicolumn{2}{c}{ Dental Caries Status } \\
\cline { 2 - 3 } & $\begin{array}{c}\text { Mean } \\
\mathrm{dft}(\mathrm{s} . \mathrm{d} .)\end{array}$ & $\begin{array}{c}\text { CFM } \\
(\%)\end{array}$ \\
\hline Occasionally but not daily $(\mathrm{n}=14)$ & $2.64(2.95)$ & 42.9 \\
Once daily ( $\mathrm{n}=82)$ & $2.11(3.60)$ & 57.3 \\
Twice daily ( $\mathrm{n}=257)$ & $2.20(3.15)$ & 47.9 \\
Three times or more daily $(\mathrm{n}=30)$ & $2.27(2.18)$ & 26.7 \\
\hline P-value ("significant) & ${ }^{*} 0.951$ & $* 0.037$ \\
\hline
\end{tabular}

brushing their children's teeth when all the primary teeth have appeared in the child's mouth which is around three years old. This showed that the majority of parents were not aware of or ignorant of the benefits of starting to clean their child's teeth at an early age. Another study by Kinnby, Palm and Widenheim (1991) revealed that tooth brushing habit was considered to be more important by those parents of the 'caries free mouth' group (5-year-olds) than the diseased group with more than 3 treated surfaces in the primary second molars (17).

Daily tooth brushing habit and an early age of onset in practising tooth brushing were observed to be associated with good oral health status $(9,18)$. Hence, parents with better perception on the importance of their children's deciduous dentition will tend to start cleaning their children's teeth at an earlier age to maintain their good oral health status with practices of good oral hygiene care habits.

The present study found that there was a reverse association between frequency of tooth-brushing and the proportion of caries free mouth. It should be noted, however that effectiveness of tooth brushing especially
Table V. Tooth brushing habit before bed time ano dental caries status

\begin{tabular}{ll}
\hline $\begin{array}{l}\text { Habit of brushing teeth } \\
\text { before bed time } \\
(N=382)\end{array}$ & $\begin{array}{c}\text { Dental Caries St } \\
\text { dft (s.d.) }\end{array}$ \\
\hline Yes ( $n=188)$ & $1.82(2.73)$ \\
Sometimes ( $n=150)$ & $2.72(3.57)$ \\
No ( $n=44)$ & $2.05(3.37)$ \\
\hline P-value ("significant) & $* 0.033$ \\
\hline
\end{tabular}

with fluoridated toothpaste is more important that frequency of tooth brushing. For example, a very proportion of the Malaysian adult population sho evidence of periodontal disease in the 1990 Nati Survey (19) inspite of their reported widespread $t$ brushing norm of more than once per day ( Moreover caries is a multifactorial disease, and $t$ is always an interaction between the various factors influence the outcome of the disease (20). There w positive relationship between the frequency of tal cariogenic food and caries prevalence irrespectivi how often the teeth were brushed (10). It seemed the benefits of tooth brushing were unable to outwe the detrimental effects of frequent sugar consump: especially when tooth brushing was not done efficie: and effectively to maintain good oral hygiene.

Children who brushed their teeth before bedtime significantly lower mean ' $\mathrm{dft}$ ' (Table V). They $c$ possessed lower proportions of 'caries free mouth' $t$ ' those children who never brushed their teeth but th differences were not statistically significant. Hower those children who never brushed their teeth bef bedtime had a higher mean ' $\mathrm{dft}$ '. This could indicative of their higher severity of dental caries sta than those who brushed their teeth before bedtime.

In conclusion, better parental oral health percept on the importance of the deciduous dentition as reflec by those parents who (a) practised regular dental cher up for their children; (b) favoured restorative treatmı for their children's decayed deciduous teeth; (c) ensuı their children brushed their teeth before bedtime : associated with better dental caries status of thr preschool children. Hence, it is recommended th greater effort should focus on promoting oral hea awareness among parents through multisector approach involving not only the dental sector but al other health sectors as well as the teachers at caretakers of the child care centres.

\section{ACKNOWLEDGMENT}

This study was undertaken as a partial fulfillment $\mathrm{f}_{\mathrm{f}}$ the degree of Master of Community Dentistry (MCD University of Malaya, Malaysia. 


\section{REFERENCES}

1. Oral Health Division, Ministry of Health Malaysia. National oral health survey of school children 1997 (NOHSS'97). Kuala Lumpur: Ministry of Health; 1998.

2. Dental Services Division, Ministry of Health Malaysia. Dental epidemiological survey of preschool children in Malaysia 1995. Kuala Lumpur: Ministry of Health; 1995.

3. Dental Services Division, Ministry of Health Malaysia: Dental epidemiological survey of school children in Peninsular Malaysia 1988. Kuala Lumpur, Government Printer, 1990.

4. Savara BS, Suher T. Dental caries in children one to six years of age as related to socio-economic level, food habits and tooth brushing. J Dent Res 1955; 34: 870-875.

5. Thomas JFG, Startup R. Social influences on the dental health behaviour of five year-olds. Health Educ J 1991; 50: 111-114.

6. Freire MCM, Meio RB, Silva SA. Dental caries prevalence in relation to socioeconomic status of nursery school children in Goiania-GO, Brazil. Community Dent Oral Epidemiol 1996, 24: 357361.

7. Blinkhorn AS. Influence of social norms on tooth brushing behaviour of preschool children. Comm Dent Oral Epidemiol 1978; 6: 222-226

8. Febres C, Echeverri EA, Keene HJ. Parental awareness, habits and social factors and their relationship to baby bottle tooth decay. Am Acad Pedia Dent 1997; 19: 22-27.

9. Verrips GH, Frenken JE, Kalsbeak H, Horst G, Filedt Kok, Weiner TL. Risk indicators and potential risk factors for caries in 5-year-old of different ethnic groups in Amsterdam. Community Dent Oral Epidemiol 1992; 20: 256-260.
10. Moynihan PJ, Holt RD. The national diet and nutrition survey of 1.5 to 4.5 year old children: summary of the findings of the dental survey. $\mathrm{Br}$ Dent J 1996; 181: 328-332.

11. Thomas JFG, Startup R. Social influnces on the dental health behaviour of five year-olds. Health Educ J 1991; 50: 111-114.

12. World Health Organisation. Oral Health Survey Basic Method, 3" Edition, Geneva: WHO, 1987.

13. Schwarz E, Lo ECM. Oral health and dental care in Hong Kong. Int Dent J 1995; 45: 169-176.

14. Esa R, Razak IA, Jallalludin RL, Jaafar N. A survey of oral health practices among Malaysian adults. Clin Prev Dent 1992; 14: 23-27.

15. Blinkhorn AS. Dental preventive advice for pregnant and nursing mothers: socio-logical implications. Int Dent J 1981; 31: 14-22.

16. Dasrilsyah S. Relationship between milk feeding habits and nursing bottle syndrome. Master of Science thesis, UPM, Faculty of Human Ecology, 1993.

17. Granath-Kinnby C, Palm L, Widenheim J. Evaluation of information on dental health care at child health centres. Differences in educational level, attitudes and knowledge among parents of preschool children with different caries experience. Acta Odontol Scand 1991; 49: 289-295.

18. Paunio P, Rautava P, Siilanpaa M, Kaleva O. Dental health habits of 3-year-old Finnish children. Community Dent Oral Epidemiol 1993; 21: 4-7.

19. Dental Services Division, Ministry of Health Malaysia: Dental epidemiological survey of adults in Malaysia 1990. Kuala Lumpur, Government Printer, 1993.

20. Winder M. Caries and the preschool child: implication within the community dental services. J.Dent 1990; 324-326. 